\title{
A flotation/sieving method to detect Echinococcus multilocularis and Toxocara spp. eggs in soil by real-time PCR
}

\author{
Gérald Umhang ${ }^{1, *}$, Matthieu Bastien ${ }^{2,3,4}$, Camille Renault ${ }^{1}$, Marine Faisse ${ }^{1,4}$, Christophe Caillot ${ }^{1}$, \\ Jean-Marc Boucher ${ }^{1}$, Vanessa Hormaz ${ }^{1}$, Marie-Lazarine Poulle ${ }^{2,3}$, and Franck Boué ${ }^{1}$ \\ 1 ANSES Nancy Laboratory for Rabies and Wildlife, National Reference Laboratory for Echinococcus spp., Wildlife Surveillance \\ and Eco-Epidemiology Unit, Technopole Agricole et Vétérinaire, 54220 Malzéville, France \\ 2 University of Reims Champagne-Ardenne, SFR Cap Santé, EA 3800 PROTAL, 51092 Reims cedex, France \\ ${ }^{3}$ University of Reims Champagne-Ardenne, CERFE, 08240 Boult-aux-Bois, France \\ ${ }^{4}$ French Establishment for Fighting Zoonoses (ELIZ), Domaine de Pixerécourt, 54220 Malzéville, France
}

Received 24 January 2017, Accepted 29 June 2017, Published online 24 July 2017

\begin{abstract}
Soil can be a source of human infection by many zoonotic helminth species including Echinococcus multilocularis and Toxocara spp. The prevention of alveolar echinococcosis could be greatly improved through the identification of at-risk areas. Yet very few data are available about the detection of E. multilocularis in soil, while more studies have been reported for Toxocara spp. Identification of soil contamination by E. multilocularis eggs requires the use of specific methods. This study describes the development of a method for the detection of E. multilocularis in soil samples with the concentration of eggs using a flotation/sieving method and detection by duplex real-time polymerase chain reaction (PCR). Toxocara spp. egg detection was also undertaken due to the widespread presence of this parasite in soil, despite it being considered less pathogenic. Method sensitivity of $100 \%$ was reached for the detection of 10 E. multilocularis eggs spiked in $10 \mathrm{~g}$ of soil. Concerning Toxocara spp., method sensitivity was lower but assumed to be due to the reduced effectiveness of the DNA extraction protocol. The parasitological status for E. multilocularis and Toxocara spp. of 63 carnivore fecal samples collected in highly endemic rural areas of France and of soil samples collected under and near these fecal samples was compared. The contamination of soil samples collected under positive fecal samples for E. multilocularis $(n=3)$ or Toxocara spp. $(n=19)$ confirmed the transfer of eggs from the definitive host to the environment.
\end{abstract}

Key words: Environmental samples, Soil contamination, Echinococcus multilocularis, Toxocara spp., Parasite eggs, Real-time PCR.

Résumé - Une méthode de flottation / tamisage pour détecter les oeufs d'Echinococcus multilocularis et Toxocara spp. dans le sol par PCR en temps réel. Le sol peut être une source d'infection humaine par de nombreuses espèces d'helminthes zoonotiques, dont Echinococcus multilocularis et Toxocara spp. La prévention de l'échinococcose alvéolaire pourrait être grandement améliorée par l'identification des zones à risque. Pourtant, très peu de données sont disponibles sur la détection d'E. multilocularis dans le sol, alors que d'autres études ont été rapportées pour Toxocara spp. L'identification de la contamination des sols par les œufs d'E. multilocularis nécessite l'utilisation de méthodes spécifiques. Cette étude décrit le développement d'une méthode pour la détection d'E. multilocularis dans les échantillons de sols avec la concentration d'oeufs en utilisant une méthode de flottation / tamisage et la détection par PCR duplex en temps réel. La détection des œufs de Toxocara spp. a également été réalisée en raison de la présence généralisée de ce parasite dans le sol, bien qu'il soit considéré comme moins pathogène. Une sensibilité méthodique de $100 \%$ a été atteinte pour la détection de dix oeufs d'E. multilocularis mélangés à dix grammes de sol. En ce qui concerne Toxocara spp., la sensibilité méthodique était inférieure mais nous supposons que cela était dû à l'efficacité réduite du protocole d'extraction d'ADN. Le statut parasitologique pour E. multilocularis et Toxocara spp. de 63 échantillons de fèces de carnivores recueillis dans des zones rurales fortement endémiques de France a été comparé à celui d'échantillons de sol prélevés en dessous ou à proximité de ces fèces. La contamination des échantillons de sol recueillis sous les échantillons fécaux positifs pour E. multilocularis $(n=3)$ ou Toxocara spp. $(n=19)$ a confirmé le transfert des œufs de l'hôte définitif vers l'environnement.

\footnotetext{
*Corresponding author: gerald.umhang@anses.fr
}

This is an Open Access article distributed under the terms of the Creative Commons Attribution License (http://creativecommons.org/licenses/by/4.0), which permits unrestricted use, distribution, and reproduction in any medium, provided the original work is properly cited. 


\section{Introduction}

More than 1.5 billion people (24\% of the world's population) are infected with soil-transmitted helminths worldwide [27]. Echinococcosis, trichinellosis, and toxoplasmosis are the main parasitic diseases of concern in Europe according to the European Food Safety Authority [17]. Among Echinococcus species, Echinococcus multilocularis, causing alveolar echinococcosis, is currently a real threat to public health in Europe, with a larger endemic area than previously thought $[7,24,30]$. Alveolar echinococcosis is caused by the oral ingestion of microscopic eggs developing into the larval stage of the tapeworm. The metacestode is made up of small chains of interconnected vesicles almost exclusively in the liver, with tumor-like, infiltrative, destructive growth [4, 11]. Humans are considered as accidental hosts of the parasite. Its lifecycle in Europe is mainly sylvatic involving red foxes (Vulpes vulpes) as definitive hosts, and small rodents as intermediate hosts. Nevertheless, concerning domestic carnivores, cats (Felis silvestris catus) and especially dogs (Canis lupus domesticus) can also act as definitive hosts after predation of infected rodents. Cats are not considered to be particularly significant due to the very low number of eggs produced during their patent period [12]. The development of worms in the intestines of definitive hosts results in the production and release of eggs to the soil via feces. Worm burden in foxes is known to be very heterogeneous with few foxes harboring the vast majority of worms, leading to a heterogeneous distribution of contaminated feces responsible for environmental contamination $[3,8,29]$. In humans, the long incubation period (from 5 to 15 years) makes the identification of the source of infection difficult or impossible. Some recurrent potential risk factors for developing alveolar echinococcosis in Europe have been identified as "dog or cat ownership," "living in a rural area," "having a kitchen garden," "farming," and "handling foxes" $[13,16,26]$. While humans can be infected through direct contact with infected carnivores having eggs on their fur or their feces, environmental contamination (soil, water, vegetables, and fruits) is thought to represent another source of infection. Many surveillance studies have been conducted in highly E. multilocularis endemic countries in Europe. These aimed to establish the prevalence of the parasite in different host species from animal samples (intestines, feces, or liver). These data provide information on the overall presence of the parasite in the different investigated areas but are not useful in identifying the source of risk for alveolar echinococcosis in humans. As feces are the primary source of infective eggs, data obtained from feces samples may constitute a proxy for describing environmental contamination by the parasite. In addition, the examination of soil contamination by E. multilocularis eggs to identify at-risk areas would result in a better understanding of the source of human infection and associated risk factors. Nevertheless, detection of taeniid eggs in feces suffers from low sensitivity by conventional routine diagnosis. The enrichment of taeniid eggs and their subsequent analysis by Polymerase Chain Reaction (PCR) by the flotation and sieving method as per Mathis et al. [21] has overcome the low sensitivity observed in conventional routine diagnosis, and opened new diagnostic strategies [2]. Difficulties related to the environmental samples may explain why only very few recent studies have focused on the identification of E. multilocularis eggs in environmental samples such as soil, vegetables, and fruits $[5,18,22,31]$. These studies have provided preliminary results that need to be confirmed by additional data.

In this context, the aim of this study was to develop a flotation/sieving method for the detection of E. multilocularis eggs in soil samples by real-time PCR, with evaluation of method sensitivity. Among the many other helminth eggs that may be found in soil, Toxocara spp. has a lifecycle also based on the release of eggs via carnivore feces to the soil and ubiquitous presence. This nematode genus is responsible for larva migrans in humans, mainly infected by environmental sources [6], and constitutes a public health problem [25]. The detection of this zoonotic parasite was thus also evaluated with the method first established for E. multilocularis. To illustrate the utilization of this method, soil samples collected under and near carnivore fecal samples were tested in order to improve our understanding of the transfer of eggs from hosts to the environment.

\section{Materials and methods}

\section{Origins of soil samples and E. multilocularis and Toxocara spp. eggs used to develop the method}

The soil used for the development of the method was sampled at the experimental station of the ANSES laboratory. No free-ranging carnivores have access to this area, allowing for the collection of soil samples free from helminth eggs. E. multilocularis eggs were obtained from a fecal sample removed from the colon of a naturally infected fox diagnosed by the sedimentation and counting technique (SCT) exhibiting no worms of the Taenia genus [29]. The fecal sample was frozen at $-20{ }^{\circ} \mathrm{C}$ until its use for isolating eggs. Additionally, the exclusive presence of E. multilocularis eggs was confirmed by PCR by the individual testing of 20 eggs randomly sampled and all confirmed to be E. multilocularis. Concerning Toxocara spp., embryonated eggs came from a fecal sample collected on the ground in the department of Moselle from a naturally infected cat. The diagnosis of Toxocara spp. was performed by real-time PCR [15] and the fecal samples frozen at $-20{ }^{\circ} \mathrm{C}$ until use. For both parasites, fecal samples were homogenized in distilled water and then filtered through a $120 \mu \mathrm{m}$ nylon mesh. After centrifugation, the supernatant was discarded and the pellet stored at $4{ }^{\circ} \mathrm{C}$ until it was suspended and observed under a stereoscopic microscope (Olympus SZX16, 250× magnification). A home-made micropipette prepared from a streamlined heparinized capillary tube (select) was used to collect the eggs one by one. The soil samples spiked with parasite eggs were stored at $4{ }^{\circ} \mathrm{C}$ for a few hours before being analyzed.

\section{Concentration of helminth eggs from the soil samples}

The flotation method involved using $10 \mathrm{~g}$ soil samples either spiked with E. multilocularis or Toxocara spp. eggs or 
samples directly collected in the environment. Samples were mixed with $10 \mathrm{~mL}$ of a $0.2 \%$ solution of Tween 20 in conical centrifuge tubes in order to facilitate the separation of eggs from soil particles. After centrifugation (1000 $\mathrm{g}, 15 \mathrm{~min}$ ), the supernatant was discarded. The pellet was suspended by mixing with $15 \mathrm{~mL}$ of a zinc chloride solution with a specific density of 1.42. After centrifugation (1000 g, $20 \mathrm{~min})$, the supernatant was transferred to be filtered on a $20 \mu \mathrm{m}$ nylon mesh (Buisine) using a suction pump. The substrate in the mesh was then rinsed with $50 \mathrm{~mL}$ of a $0.2 \%$ Tween 20 solution above a funnel placed on a centrifugation tube. A new mesh was used for each sample. After new centrifugation (1000 g, $15 \mathrm{~min}$ ), the supernatant was discarded and a pellet of approximately $1 \mathrm{~mL}$ retained to undergo DNA extraction. In the context of the method's development, samples of $20 \mathrm{~g}$ of soil were also tested for E. multilocularis. The same flotation protocol was applied but volumes were doubled for the initial step of Tween 20 and for zinc chloride. All transfers of solution and samples were performed with new sterile pipettes to prevent any contamination between samples.

\section{DNA extraction and qPCR assays}

DNA extraction from pellets of soil samples was undertaken using the NucleoSpin Tissue kit (Macherey-Nagel) as recommended by the manufacturer. The detection of DNA from both E. multilocularis and Toxocara spp. was undertaken by real-time PCR (qPCR) as previously described [14, 15]. The two qPCRs were performed as one multiplex reaction, also including detection of an internal control [33]. However, a different probe was used to specifically identify each source of DNA. A final qPCR volume of $25 \mu \mathrm{L}$ was used, containing $5 \mu \mathrm{L}$ of DNA, $12.5 \mu \mathrm{L}$ of Master Mix Maxima Probe, 50 copies of the internal control plasmid, $0.6 \mu \mathrm{M}$ of primers for E. multilocularis, $0.3 \mu \mathrm{M}$ of primers for Toxocara spp., and $0.25 \mu \mathrm{M}$ for the three probes (E. multilocularis, Toxocara spp., and internal control). The qPCRs were performed in duplicate and run on a RotorGene thermocycler (Qiagen) with a program that consists of $10 \mathrm{~min}$ at $95{ }^{\circ} \mathrm{C}$ and 45 cycles of $15 \mathrm{~s}$ at $95{ }^{\circ} \mathrm{C}$ and $60 \mathrm{~s}$ at $60{ }^{\circ} \mathrm{C}$. All E. multilocularis-positive copro-samples obtained by real-time PCR were confirmed by sequencing the PCR products of a second real-time PCR, performed on the same gene, as proposed by Knapp et al. [15]. Briefly, the same qPCR was performed but using a new reverse primer to obtain a longer fragment. If this second qPCR is also positive, the amplicon was amplified again by a classic PCR using the same primers as the second qPCR to facilitate the sequencing. Concerning the analysis of fecal samples, $500 \mathrm{mg}$ was subject to DNA extraction using the QIAamp DNA Stool Mini Kit (Qiagen), following the suggested protocols of the manufacturer. The molecular identification of the carnivore host species (i.e. fox, dog, cat) based on the fecal samples was performed as previously described [15]. Briefly, a specific couple of primers and a probe were designed for the $c o b$ gene of each of the three species. The qPCR was carried out in multiplex in a final volume of $25 \mu \mathrm{L}$, containing $2 \mu \mathrm{L}$ of DNA, $12.5 \mu \mathrm{L}$ of Master Mix
Maxima Probe, $30 \mathrm{nM}$ of Rox, $0.4 \mu \mathrm{M}$ of forward and reverse primers, $0.1 \mu \mathrm{M}$ of probes used for fox and dog, and $0.2 \mu \mathrm{M}$ of probe used for cat. An Mx3005P thermocycler (Agilent) was used with a program that consists of $10 \mathrm{~min}$ at $95^{\circ} \mathrm{C}$ and 45 cycles of $15 \mathrm{~s}$ at $95{ }^{\circ} \mathrm{C}$ and $60 \mathrm{~s}$ at $60{ }^{\circ} \mathrm{C}$. Detection of DNA from E. multilocularis and Toxocara spp. was undertaken according to the same real-time PCR protocol described for soil samples.

\section{Determination of method sensitivity}

The effectiveness of DNA extraction followed by detection with real-time PCRs was evaluated by testing several replicates of samples containing only distilled water with 10 eggs $(n=2)$, five eggs $(n=2)$, three eggs $(n=6)$, and one egg $(n=10)$. Secondly, the sensitivity of the method was tested throughout the process, from flotation to qPCRs, using soil samples spiked with 10 eggs, five eggs, three eggs, and one egg of both parasites. The protocol was initially designed and developed to be able to detect $10 \mathrm{E}$. multilocularis eggs in $10 \mathrm{~g}$ of soil with a minimum sensitivity of $90 \%$. This protocol was then applied for the evaluation of sensitivity to detect eggs of Toxocara spp.

\section{Detection in soil samples under and near carnivore fecal samples}

Fecal and soil samples were collected in OctoberNovember 2015 to test the developed method. The collection was carried out at 49 sites located in two E. multilocularis endemic areas of north-eastern France, Ardennes and Moselle, with $36 \%$ and $34 \%$ of foxes infected, respectively [1]. One fecal sample was collected per site except for four sites where two fecal samples $(n=10)$ and three fecal samples $(n=2)$ were collected for a total of 63 carnivore fecal samples collected (Fig. 1). The carnivore origin of the fecal samples was systematically confirmed by real-time PCR. One soil sample was collected at the exact place where a fecal sample was found and a second soil sample was also taken between $50 \mathrm{~cm}$ and $1 \mathrm{~m}$ from the first one. A soil sample corresponding to roughly $50 \mathrm{~g}$ of soil was collected over approximately the first $5 \mathrm{~cm}$ of the surface, and over a surface area of approximately $10 \mathrm{~cm}^{2}$. The soil samples were stored frozen in a plastic zip bag. For analysis, $10 \mathrm{~g}$ was used after brief manual homogenization through the plastic bag. In total, two soil samples were collected for each fecal sample leading to 126 soil samples. Levels of the parasites were assessed both in the fecal and soil samples after storage for one week at $-80{ }^{\circ} \mathrm{C}$ to prevent human infection. The link between the presence of fecal samples, regardless of their parasitological status or only considering positive fecal samples for E. multilocularis and/or Toxocara spp., and soil contamination was assessed using chi-square tests, or using Fisher's exact test when there were not enough samples. All statistical analyses were performed using the statistical software program R 3.1.3 [28] (with a significance threshold of 0.05 ). 


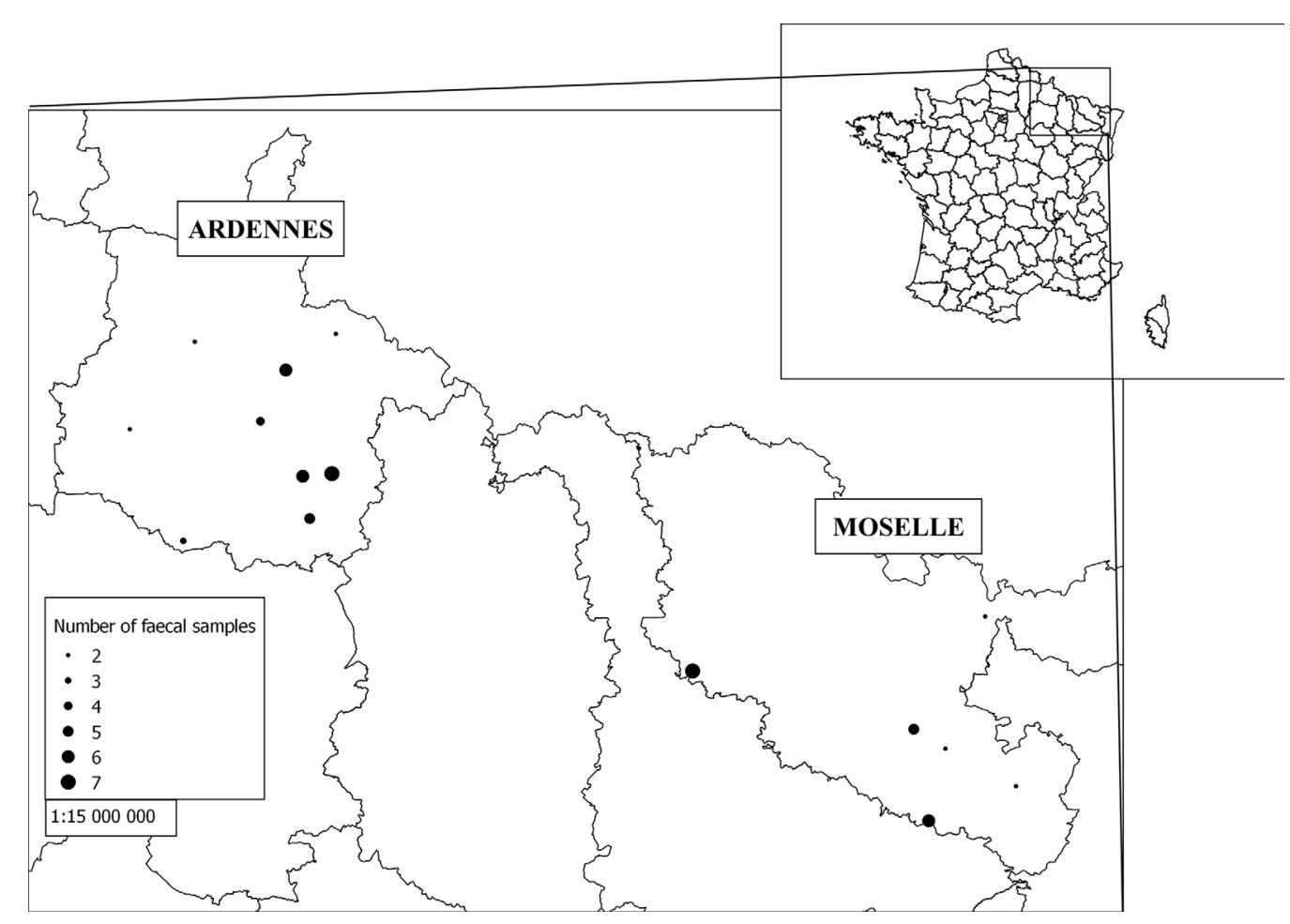

Figure 1. Geographical distribution of the collected feces. For each fecal sample, one soil sample was collected under the fecal sample and another one between $50 \mathrm{~cm}$ and $1 \mathrm{~m}$ from the first one.

\section{Results}

\section{Sensitivity of the method for detection of E. multilocularis and Toxocara spp. eggs}

All E. multilocularis eggs in distilled water samples (from 10 eggs to 1 egg) directly subjected to DNA extraction and real-time PCR were detected. Average quantification cycle (Cq) values ranged from 26.43 for 10 eggs to 30.99 for one egg. A low standard deviation even for one egg $(S D=1.1)$ provided evidence of the high effectiveness and repeatability of these molecular steps. On the other hand, while all samples with 10 and five Toxocara spp. eggs in distilled water also led to a positive result, amplification was observed for only three out of the five samples with three eggs $(60 \%)$, and for only three out of the 10 samples with one egg (30\%). When testing naive soil samples of $10 \mathrm{~g}$ spiked with 10 E. multilocularis eggs, a positive qPCR signal was obtained for all samples, corresponding to $100 \%$ sensitivity (Table 1 ). When using five eggs to one egg, sensitivity decreased from $80 \%$ to $33.3 \%$. Using $20 \mathrm{~g}$ of soil also resulted in lower sensitivity for detecting E. multilocularis eggs. For Toxocara spp., the sensitivity obtained with spiked soil samples (10 g) ranged from $41.7 \%$ for 10 eggs to only $8.3 \%$ for one egg (Table 1 ).

\section{Detection of parasitic DNA under and near fecal samples}

Among the 63 collected fecal samples, DNA from Toxocara spp. was identified in 19 samples (30.2\%), mainly
Table 1. Method sensitivities (in \%) of the flotation/sieving method combined with DNA extraction and detection by real-time PCR for E. multilocularis and Toxocara spp. in soil samples (10 g or $20 \mathrm{~g}$ ). For each number of eggs, 15 and 12 samples were used for E. multilocularis and Toxocara spp., respectively.

\begin{tabular}{|c|c|c|c|}
\hline \multirow{2}{*}{$\begin{array}{l}\text { Number of } \\
\text { eggs }\end{array}$} & \multicolumn{2}{|c|}{ E. multilocularis } & \multirow{2}{*}{$\frac{\text { Toxocara spp. }}{10 \mathrm{~g}}$} \\
\hline & $10 \mathrm{~g}$ & $20 \mathrm{~g}$ & \\
\hline 1 & $33.3 \%(5 / 15)$ & NA & $8.3 \%(1 / 12)$ \\
\hline 2 & $66.7 \%(10 / 15)$ & NA & $25.0 \%(3 / 12)$ \\
\hline 5 & $80.0 \%(12 /$ & $73.3 \%(11$ & $8.3 \%(1 / 12)$ \\
\hline 10 & $100.0 \%(15 / 15)$ & $86.7 \%(13 / 15)$ & $41.7 \%(5 / 12)$ \\
\hline
\end{tabular}

from cat fecal samples (Table 2). E. multilocularis was detected in only three fecal samples from foxes $(4.8 \%$ of all collected fecal samples). Overall, E. multilocularis and Toxocara spp. were detected in 15 (11.7\%) and 11 (8.6\%) soil samples, respectively. Toxocara spp. and E. multilocularis were identified together only in one soil sample collected under a fox fecal sample positive for E. multilocularis but not for Toxocara spp. No inhibition was observed for fecal or soil samples. Due to the low number of fecal samples contaminated with eggs of E. multilocularis, the two parasites were considered together when studying links between fecal and soil sample contamination statuses (Table 3). When comparing parasite contamination in fecal and associated soil samples, a positive correlation was found only for the detection of the same parasite (i.e. E. multilocularis or Toxocara spp.) in both fecal and soil samples. Soil contamination by Toxocara spp. 
Table 2. E. multilocularis and Toxocara spp. infection level of feces collected in kitchen gardens depending on the carnivore species identified.

\begin{tabular}{lcccc}
\hline & \multicolumn{3}{c}{ Carnivore species feces identification } & \multicolumn{1}{c}{ Total } \\
\cline { 2 - 4 } & Fox & Cat & Dog & $3(4.8 \%)$ \\
\hline E. multilocularis & $3(12.0 \%)$ & 0 & $1(33.3 \%)$ & $19(30.2 \%)$ \\
Toxocara spp. & $1(4.0 \%)$ & $17(48.6 \%)$ & 3 & 63 \\
Number of feces & 25 & 35 & & 3 \\
\hline
\end{tabular}

Table 3. Parasitological status for E. multilocularis and Toxocara spp. of fecal and soil samples depending on their position under or near the feces.

\begin{tabular}{lcccc}
\hline Parasitological status of fecal samples & \multicolumn{2}{c}{ Parasitological status of soil samples } \\
\cline { 2 - 3 } & \multicolumn{2}{c}{ Under the feces } & \multicolumn{2}{c}{ Near the feces } \\
\cline { 2 - 3 } & E. multilocularis & Toxocara spp. & E. multilocularis & 1 \\
\hline Positive E. multilocularis $(n=3)$ & 1 & 7 & 1 & 1 \\
Positive Toxocara spp. $(n=19)$ & 3 & 1 & 5 & 1 \\
Negative $(n=41)$ & 5 & 7 & 1 \\
\hline
\end{tabular}

Table 4. Parasitological status (E. multilocularis and/or Toxocara spp.) of soil samples depending on where they were collected (under or near a fecal sample) and the parasitological status of the fecal sample. A positive correlation for the parasitological status was considered present only for the detection of the same parasite (i.e. E. multilocularis or Toxocara spp.) in both fecal and soil samples.

\begin{tabular}{lcccccc}
\hline & \multicolumn{2}{c}{ Positive soil samples } & & \multicolumn{2}{c}{ Negative soil samples } \\
\cline { 2 - 3 } \cline { 5 - 6 } & Under fecal samples & Near fecal samples & & Under fecal samples & Near fecal samples \\
\hline Positive fecal samples $(n=22)$ & 10 & 4 & 12 & 18 & $\chi^{2}, p=0.018$ \\
Negative fecal samples $(n=41)$ & 6 & 6 & 35 & 35 & OR, $p=0.729$ \\
\hline
\end{tabular}

or E. multilocularis was not related to the presence of feces, regardless of the parasitological status of the fecal samples $\left(\chi^{2}=1.21 ; p=0.271\right)$ : positive soil was found in places where there was a scat (with or without parasites) as well as in places where there was not. Nevertheless, soil samples collected under positive fecal samples for Toxocara spp. or E. multilocularis were significantly more contaminated by the respective parasite species than the soil samples collected near these positive fecal samples $\left(\chi^{2}=5.64 ; p=0.018\right)$. By contrast, soil samples collected under non-contaminated fecal samples were not more contaminated than soil samples collected near non-contaminated fecal samples $(\mathrm{OR}=1.21$; $p=0.729)$ (Table 4).

\section{Discussion}

The flotation/sieving method combined with qPCR detection developed in this study proved to have sensitivity of $100 \%$ for the detection of 10 eggs of E. multilocularis in $10 \mathrm{~g}$ of soil sample. Additionally, it enabled the potential detection of only one egg in $10 \mathrm{~g}$ of soil sample. Evaluation of the method's sensitivity appears essential before it can be used in field studies to draw relevant epidemiological conclusions. The use of $10 \mathrm{~g}$ of soil appeared to be more sensitive than the use of $20 \mathrm{~g}$, even though there was no significant difference due to the low number of samples tested $(n=15)$. Using a higher quantity may be difficult and time-consuming for logistical reasons in the processing of the flotation/sieving technique, requiring the construction of specific in-house material [9], and may also reduce sensitivity. Collecting multiple samples of $10 \mathrm{~g}$ at different places may provide a better overview of contamination in an area than a single sample of a higher amount due to expected heterogeneity in the spatial distribution of the eggs. Furthermore, the relatively high level of E. multilocularis and Toxocara spp. eggs in $10 \mathrm{~g}$ soil samples from this study ( $11.7 \%$ and $8.6 \%$, respectively) supports the use of this amount.

The method proved to be less sensitive for the detection of Toxocara spp. eggs compared to E. multilocularis. Positive amplification results were not systematically obtained after direct DNA extraction of less than five Toxocara spp. eggs. This step is most likely the reason for the lower sensitivity in detecting Toxocara spp. eggs in soil samples, rather than the flotation/sieving step as further adaptation of the DNA extraction protocol by increasing the lysis period resolved this issue. Additional tests of DNA extraction from several samples of one Toxocara spp. egg isolated from cat and fox fecal samples systematically resulted in a positive qPCR signal. Unfortunately, this modification could not be applied to the environmental samples tested since the protocol used was the one initially designed for E. multilocularis. Thus, the number 
of positive environmental samples for Toxocara spp. is probably underestimated in this study. Microscopic identification of the eggs instead of molecular diagnosis may also resolve this issue for Toxocara spp. While this visual identification is also possible for many other parasite genera, molecular identification is essential for taeniid eggs in order to distinguish between the Taenia and Echinococcus genera and precisely determine the species involved. Additionally, the use for soil samples of a DNA fishing method for the detection of E. multilocularis already developed for feces $[10,20]$ may improve the sensitivity of the protocol.

The method was tested with soil samples collected under and near fecal samples to assess a potential link between the detection of eggs and the observation of a fecal sample, assuming a potential transfer of eggs from the infected feces to the soil notably via rain washing. Due to the low number of positive fecal samples for E. multilocularis, data for both E. multilocularis and Toxocara spp. were considered, but assuming that the results obtained here are transposable to E. multilocularis alone. Based on our results, the detection of feces does not appear to be an absolute indicator of soil contamination but may only be an indicator of risk exposure to parasites. On the other hand, the more frequent contamination of soil samples collected under positive fecal samples for E. multilocularis or Toxocara spp., compared to soil samples collected near these fecal samples, confirms the transfer of eggs from the definitive host to the environment. Although this result was expected, it confirms the reliability of the developed method. Removal of feces was previously described as an important way to decrease Toxocara spp. egg contamination [23]. In a context of soil contamination prevention, simply removing the observed feces may not be completely effective and efforts should focus on restricting access to these sensitive areas by carnivores.

Very few data are currently available on E. multilocularis and other Echinococcus species in soil and other environmental samples. Other methods for detecting E. multilocularis in environmental samples, as recently undertaken in vegetables and fruits [5], need to be developed. As some reliable methods are now available, further studies are needed to evaluate actual environmental contamination in places where humans are often in contact with soil, such as kitchen gardens and public parks, and to evaluate the potential seasonal variation of this contamination. Additionally, quantitative estimation of the viability of E. multilocularis eggs in soil as already performed for Toxoplasma gondii [19] will also be of particular interest, especially considering the accumulation of eggs over time. The evaluation of $E$. multilocularis in environmental samples such as soil, vegetables, fruits, and water can improve our understanding of sources of human cases of alveolar echinococcosis.

\section{References}

1. Combes B, Comte S, Raton V, Raoul F, Boue F, Umhang G, Favier S, Dunoyer C, Woronoff N, Giraudoux P. 2012. Westward spread of Echinococcus multilocularis in foxes, France, 2005-2010. Emerging Infectious Diseases, 18(12), 2059-2062.
2. Conraths FJ, Deplazes P. 2015. Echinococcus multilocularis: epidemiology, surveillance and state-of-the-art diagnostics from a veterinary public health perspective. Veterinary Parasitology, 213(3-4), 149-161.

3. Deplazes P, Hegglin D, Gloor S, Romig T. 2004. Wilderness in the city: the urbanization of Echinococcus multilocularis. Trends in Parasitology, 20(2), 77-84.

4. Eckert J, Gemmell MA, Meslin FX, Pawlowski ZS. 2001. WHO/OIE Manual on echinococcosis in humans and animals: a public health problem of global concern. Paris: O.I.E. - O.M.S. p. 265.

5. Federer K, Armua-Fernandez MT, Gori F, Hoby S, Wenker C, Deplazes P. 2016. Detection of taeniid (Taenia spp., Echinococcus spp.) eggs contaminating vegetables and fruits sold in European markets and the risk for metacestode infections in captive primates. International Journal for Parasitology: Parasites and Wildlife, 5(3), 249-253.

6. Glickman LT, Shofer FS. 1987. Zoonotic visceral and ocular larva migrans. Veterinary Clinics of North America: Small Animal Practice, 17(1), 39-53.

7. Gottstein B, Stojkovic M, Vuitton DA, Millon L, Marcinkute A, Deplazes P. 2015. Threat of alveolar echinococcosis to public health - a challenge for Europe. Trends in Parasitology, 31(9), 407-412.

8. Hofer S, Gloor S, Müller U, Mathis A, Hegglin D, Deplazes P. 2000. High prevalence of Echinococcus multilocularis in urban red foxes (Vulpes vulpes) and voles (Arvicola terrestris) in the city of Zurich, Switzerland. Parasitology, 120(2), 135-142.

9. Horiuchi S, Uga S. 2016. Modified flotation method, an effective technique for recovering helminth eggs in soil. Parasitology International, 65, 576-579.

10. Isaksson M, Hagstrom A, Armua-Fernandez M, Wahlstrom H, Agren E, Miller A, Holmberg A, Lukacs M, Casulli A, Deplazes P, Juremalm M. 2014. A semi-automated magnetic capture probe based DNA extraction and real-time PCR method applied in the Swedish surveillance of Echinococcus multilocularis in red fox (Vulpes vulpes) faecal samples. Parasites and Vectors, 7(1), 583.

11. Jenkins DJ, Romig T, Thompson RC. 2005. Emergence/ re-emergence of Echinococcus spp. - a global update. International Journal for Parasitology, 35(11-12), 1205-1219.

12. Kapel CM, Torgerson PR, Thompson RC, Deplazes P. 2006. Reproductive potential of Echinococcus multilocularis in experimentally infected foxes, dogs, raccoon dogs and cats. International Journal forParasitology, 36(1), 79-86.

13. Kern P, Ammon A, Kron M, Sinn G, Sander S, Petersen LR, Gaus W. 2004. Risk factors for alveolar echinococcosis in humans. Emerging Infectious Diseases, 10(12), 2088-2093.

14. Knapp J, Millon L, Mouzon L, Umhang G, Raoul F, Said Ali Z, Combes B, Comte S, Gbaguidi-Haore H, Grenouillet F, Giraudoux P. 2014. Real time PCR to detect the environmental faecal contamination by Echinococcus multilocularis from red fox stools. Veterinary Parasitology, 201(1-2), 40-47.

15. Knapp J, Umhang G, Poulle ML, Millon L. 2016. Development of a real-time PCR for a sensitive one-step copro-diagnosis allowing both the identification of carnivore feces and the detection of Toxocara spp. and Echinococcus multilocularis. Applied and Environmental Microbiology, 82(10), 2950-2958.

16. Kreidl P, Allerberger F, Judmaier G, Auer H, Aspöck H, Hall AJ. 1998. Domestic pets as risk factors for alveolar hydatid disease in Austria. American Journal of Epidemiology, 147(10), 978-981. 
17. Lahuerta A, Westrell T, Takkinen J, Boelaert F, Rizzi V, Helwigh B, Borck B, Korsgaard H, Ammon A, Mäkelä P. 2011. Zoonoses in the european union: origin, distribution and dynamics - the EFSA-ECDC summary report 2009. Eurosurveillance, 16(13), 1-4.

18. Lass A, Szostakowska B, Myjak P, Korzeniewski K. 2015. The first detection of Echinococcus multilocularis DNA in environmental fruit, vegetable, and mushroom samples using nested PCR. Parasitology Research, 114(11), 4023-4029.

19. Lelu M, Villena I, Darde ML, Aubert D, Geers R, Dupuis E, Marnef F, Poulle ML, Gotteland C, Dumetre A, Gilot-Fromont E. 2012. Quantitative estimation of the viability of Toxoplasma gondii oocysts in soil. Applied and Environmental Microbiology, 78(15), 5127-5132.

20. Maas M, van Roon A, Dam-Deisz C, Opsteegh M, Massolo A, Deksne G, Teunis P, van der Giessen J. 2016. Evaluation by latent class analysis of a magnetic capture based DNA extraction followed by real-time qPCR as a new diagnostic method for detection of Echinococcus multilocularis in definitive hosts. Veterinary Parasitology, 230, 20-24.

21. Mathis A, Deplazes P, Eckert J. 1996. An improved test system for PCR-based specific detection of Echinococcus multilocularis eggs. Journal of Helminthology, 70(3), 219-222.

22. Matsuo K, Kamiya H. 2005. Modified sugar centrifugal flotation technique for recovering Echinococcus multilocularis eggs from soil. Journal of Parasitology, 91(1), 208-209.

23. Morgan ER, Azam D, Pegler K. 2013. Quantifying sources of environmental contamination with Toxocara spp. eggs. Veterinary Parasitology, 193(4), 390-397.

24. Oksanen A, Siles-Lucas M, Karamon J, Possenti A, Conraths FJ, Romig T, Wysocki P, Mannocci A, Mipatrini D, La Torre G, Boufana B, Casulli A. 2016. The geographical distribution and prevalence of Echinococcus multilocularis in animals in the
European Union and adjacent countries: a systematic review and meta-analysis. Parasites \& Vectors, 9(1), 1-23.

25. Overgaauw PAM, van Knapen F. 2008. Toxocarosis, an important zoonosis. European Journal of Companion Animal Practice, 18(3), 259-266.

26. Piarroux M, Piarroux R, Knapp J, Dumortier J, Watelet J, Gerard A, Beytout J, Abergel A, Bresson Hadni S, Gaudart J. 2013. Populations at risk for alveolar echinococcosis, France. Emerging Infectious Diseases, 19(5), 721-728.

27. Pullan RL, Smith JL, Jasrasaria R, Brooker SJ. 2014. Global numbers of infection and disease burden of soil transmitted helminth infections in 2010. Parasites \& Vectors, 7, 1-19.

28. R Core Team. 2015. R: a language and environment for statistical computing. Vienna, Austria: R Foundation for Statistical Computing.

29. Robardet E, Giraudoux P, Caillot C, Boué F, Cliquet F, Augot D, Barrat J. 2008. Infection of foxes by Echinococcus multilocularis in urban and suburban areas of Nancy, France: Influence of feeding habits and environment. Parasite, 15(1), 77-85.

30. Romig T. 2009. Echinococcus multilocularis in Europe - state of the art. Veterinary Research Communications, 33(Suppl 1), 31-34.

31. Szostakowska B, Lass A, Kostyra K, Pietkiewicz H, Myjak P. 2014. First finding of Echinococcus multilocularis DNA in soil: preliminary survey in Varmia-Masuria Province, northeast Poland. Veterinary Parasitology, 203(1-2), 73-79.

32. Umhang G, Forin Wiart M-A, Hormaz V, Caillot C, Boucher J-M, Poulle M-L, Boué F. 2015. Echinococcus multilocularis detection in the intestines and feces of freeranging domestic cats (Felis s. catus) and European wildcats (Felis s. silvestris) from northeastern France. Veterinary Parasitology, 214(1-2), 75-79.

Cite this article as: Umhang G, Bastien M, Renault C, Faisse M, Caillot C, Boucher J-M, Hormaz V, Poulle M-L \& Boué F: A flotation/ sieving method to detect Echinococcus multilocularis and Toxocara spp. eggs in soil by real-time PCR. Parasite, $2017,24,28$.

\section{PARASTE}

An international open-access, peer-reviewed, online journal publishing high quality papers on all aspects of human and animal parasitology

Reviews, articles and short notes may be submitted. Fields include, but are not limited to: general, medical and veterinary parasitology; morphology, including ultrastructure; parasite systematics, including entomology, acarology, helminthology and protistology, and molecular analyses; molecular biology and biochemistry; immunology of parasitic diseases; host-parasite relationships; ecology and life history of parasites; epidemiology; therapeutics; new diagnostic tools.

All papers in Parasite are published in English. Manuscripts should have a broad interest and must not have been published or submitted elsewhere. No limit is imposed on the length of manuscripts.

Parasite (open-access) continues Parasite (print and online editions, 1994-2012) and Annales de Parasitologie Humaine et Comparée (1923-1993) and is the official journal of the Société Française de Parasitologie. 